\title{
Mobilidade sustentável: Teoria e prática no Brasil.
}

Sustainable mobility: Theory and practice in Brazil.

Movilidad sostenible: Teoría y práctica en Brasil.

\author{
Eloisa Carvalho de Araujo \\ Professor Doutor, EAU/UFF, Brasil. \\ eloisa.araujo@gmail.com
}

\section{Gabriela Mesquita Ramalho dos Santos}

Mestranda, EAU/UFF, Brasil. arq.gabrielamesquita@gmail.com

\section{Poliana de Souza Borges França}

Mestranda, EAU/UFF, Brasil. polianaszborges@gmail.com 


\section{RESUMO}

A mobilidade tem sido considerada um elemento central para se pensar e planejar a cidade. Nos últimos anos tem se visto uma crescente dependência da mobilidade para atividades básicas econômicas e sociais. 0 tema deste artigo se insere na discussão sobre mobilidade e suas implicações. Por um viés interdisciplinar a pesquisa em curso busca apoiar-se no diálogo entre relações sociais e ambientais e como a gestão pública tem lidado com essas questões, onde fluxos e contrafluxos revelam a cidade contemporânea. Movimentos da cotidianidade redefinem as pressões e tensões sobre o território, assim como, com potencial criativo, a formação de visões de mundo. Busca-se com esse artigo contribuir com as pesquisas sobre a tendência da utilização da mobilidade dentro da gestão pública.

PALAVRAS-CHAVE: Mobilidade urbana, gestão pública, sustentabilidade

\section{ABSTRACT}

Mobility is a central element in thinking and planning the city. In recent years, we have seen once a rise dependency of mobility on basic economic and social activities. The theme of this article is about mobility and its implications. Through an interdisciplinary approach the research is based on the dialogue between social and environmental relations and how the public management have being considering these issues, where flows and counterflows reveal a contemporary city. Movements of daily life redefined as pressures and actions on the territory, as well as, with creative potential, the formation of visions of the world. Publication suggestions on how to use the mobility capacity within the public company

\section{KEY WORDS: Urban mobility, public management, sustainability}

\section{RESUMEN}

La movilidad se ha considerado un elemento central para pensar y planificar la ciudad. En los últimos años se ha visto una creciente dependencia de la movilidad para actividades básicas económicas y sociales. El tema de este artículo se inserta en la discusión sobre movilidad y sus implicaciones. Por un sesgo interdisciplinario la investigación en curso busca apoyarse en el diálogo entre relaciones sociales y ambientales y cómo la gestión pública ha manejado con esas cuestiones, donde flujos y contraflujos revelan la ciudad contemporánea. Movimientos de la cotidianidad redefinen las presiones y tensiones sobre el territorio, así como, con potencial creativo, la formación de visiones de mundo. Se busca con este artículo contribuir con las investigaciones sobre la tendencia de la utilización de la movilidad dentro de la gestión pública.

PALABRAS CLAVE: Movilidad urbana, gestión pública, sostenibilidad 


\section{INTRODUÇÃO}

O tema deste artigo insere-se na experiência dos deslocamentos urbanos, como prática de descobrir a cidade. Por um viés interdisciplinar a pesquisa em curso busca apoiar-se no diálogo entre relações sociais e ambientais e gestão pública, onde fluxos e contrafluxos revelam a cidade contemporânea. Movimentos da cotidianidade redefinem as pressões e tensões sobre o território, assim como, com potencial criativo, a formação de visões de mundo.

Partindo de pesquisas empíricas, as autoras pretendem ressaltar o papel exercido pelos deslocamentos na cidade: os desafios impostos, as inspirações que os movem e as questões estruturais associadas.

Para muitos a mobilidade vai além do deslocamento ${ }^{1}$, quando ressaltam que o automóvel não pode mais ser visto como elemento essencial para a mobilidade urbana. Por outro, a visão de uma cidade integrada, com vitalidade e sustentabilidade, deve primar pela oferta de espaços públicos não somente destinados a espaços de circulação, mas, sobretudo, como espaços que compartilhem relações sociais, como espaços de sociabilidade. E nesse sentido, compartilhar espaços tem sido um dos maiores desafios da cidade contemporânea, no sentido de reforçar a qualidade de vida, propiciando percorrer a cidade, em sua complexidade e diversidade, para satisfazer movimentos e necessidades.

O Brasil se tornou um país com o sistema de transporte baseado apenas na esfera dos veículos automotores, houve um grande estímulo desde a década de 1950 (VASCONCELLOS, 2013), quando obteve um crescimento acelerado de sua economia, resultado de um processo de industrialização do país. Os centros urbanos se expandiram e o arranjo das cidades brasileiras sofreu grande impacto. Com o incentivo ao transporte automotivo individual (como obras de ampliação do sistema viário e incentivos fiscais para a indústria automobilística), o padrão de deslocamento da população passou por grandes transformações.

O modelo de mobilidade adotado na década de 50 impactou a vida urbana nas principais cidades brasileiras, deixando consequências na distribuição da população, oferta de emprego e o aumento do tempo dos deslocamentos dos trabalhadores.

Segundo a arquiteta e urbanista Ermínia Maricato ${ }^{2}$, o Brasil vive um cenário de cidades inviáveis e insustentáveis, levado pelo crescimento imobiliário e automobilístico entre os anos de 2009 e 2014. Para entender esse aspecto basta um olhar para os dados de trânsito que mostram as 40 mil mortes por ano, segundo a mesma. 0 problema toca às questões sociais, econômicas e ambientais, demonstrando um conjunto de fatores que evidenciam a crise de mobilidade que permanece no país.

\footnotetext{
${ }^{1}$ Ver em: https://observasp.wordpress.com/2016/08/11/mobilidade-urbana-muito-alem-dodeslocamento/. Acesso em 20 de maio de 2018.

${ }^{2}$ MARICATO, Ermínia. Diálogos: Ermínia Maricato. 1. 2018. Disponível em: <https://www.youtube.com/watch?v=9MvqeZi1Qko\&feature=youtu.be>. Acesso em: 01 jun. 2018.
} 


\section{OBJETIVOS}

O deslocamento humano no cenário atual tem se baseado em estratégias fechadas em projetos de cidade que não condizem com as necessidades atuais dos habitantes. Sistemas tarifários caros, transportes precários e sem previsibilidade de horário, perda de opções de deslocamento, falta de abastecimento por falta de combustível entre outros. O artigo tem como objetivo debater sobre a temática da liberdade de ir e vir condicionadas às produção do espaço urbano, políticas públicas e gestão das cidades.

Soluções globais de projetos para uma cidade inteira são implantadas e afetam escalas locais, como gerir essas novas mudanças e propor novas práticas para a cidade? 0 objetivo do artigo é olhar sobre os aspectos da mobilidade, gestão pública e relações humanas e como essas questões se articulam favorecendo ou não a possibilidade do deslocamento democrático.

\section{METODOLOGIA}

A pesquisa a seguir é uma vertente das pesquisas realizadas no Laboratório da Paisagem da Universidade Federal Fluminense que tem como objetivo estudar a produção do espaço urbano entre suas diversas variáveis. O método escolhido é uma investigação teórica com abordagem dedutiva, baseada em levantamento de referencial bibliográfico. $\mathrm{O}$ artigo aborda a primeira etapa da pesquisa: o diagnóstico do sistema de mobilidade nas cidades brasileiras. Se dará continuidade da pesquisa a partir do aprofundamento das questões ressaltadas neste artigo assim como a apresentação e discussão de políticas públicas que corroborem para um desenvolvimento urbano sustentável.

\section{SISTEMAS DE MOBILIDADE}

A mobilidade urbana tem sido considerada um tema chave para se discutir políticas públicas, o estilo de vida urbano e práticas empresariais estão cada vez mais associados e dependentes dela e ao mesmo tempo seus impactos negativos no ambiente natural e social tem aumentado dramaticamente (BERTOLINI,2012). Ela, associada a evolução tecnológica sempre foram os pontos determinantes para a fixação dos humanos no território, pois é vital a capacidade de deslocamento para atividades básicas como a realização trocas econômicas e sociais. 0 planejamento da mobilidade no cenário mundial já se consolida como ferramenta de gestão do território, permitindo tratar as várias problemáticas urbanas como o uso e ocupação do solo, estímulo de centralidades e espraiamento urbano.

Segundo Born (2011) a mobilidade é um atributo associado às pessoas e aos bens e correspondem às diferentes respostas dadas por indivíduos e agentes econômicos às suas necessidades de deslocamento, considerada as dimensões do espaço urbano e a complexidade das atividades neles desenvolvidas. Contudo Bertolini (2012) aponta que mesmo que a mobilidade esteja se transformando em objeto central de planejamento, muitas implicações 
não são desenhadas e a mobilidade continua sendo considerada um dos vários elementos de preocupação do planejamento urbano e não o elemento central.

Por exemplo, quando confrontada a definição de mobilidade com as práticas reais da cidade é possível ver que ao passo em que se fortalecem as redes de mobilidade para algumas pessoas ou grupos, outras por não se adequarem a rede proposta tendem a entrar em uma uma rede de imobilidade.

Isso acontece porque a mobilidade extrapola o sentido de deslocamento físico. Segundo Balbim (2016) mesmo que por muito tempo seu significado tenha se confundido com acessibilidade, trânsito ou transporte, seu sentido se alterou de modo que todas as formas de mobilidade, seja ela de migração, deslocamentos pendulares ou a própria mobilidade social tem relação direta com a divisão social e territorial do trabalho e também aos modos de produção. Nesse sentido, Bertolini (2012) fala que a mobilidade ao mesmo tempo que trás a liberdade do ir e vir também se torna uma necessidade pois sem ela não podemos ter acesso nem aos serviços básicos nem a participação na vida econômica e social. Potencializar a mobilidade passa ser a uma questão para se democratizar a cidade e a circulação em escalas completamente distintas seja na escala local, regional ou nacional.

A questão mobilidade passa a ganhar tanta força em vários campos da ciência que começa a ser discutido além do âmbito físico-geográfico. Autores como Mimi Sheller e John Urry (2006) vão trazer a tona a "virada da mobilidade", quando ela sai da pesquisa de transportes e passa a dominar vários campos das ciências humanas como antropologia, geografia e estudos de migração. Os autores questionam alguns paradigmas da mobilidade baseados em questões do mundo contemporâneo como por exemplo o fato das relações sociais não terem dependência exclusivamente do contato físico, ou da ideia superada de que a distância levava a um desgoverno. Sheller e Urry mostram que existe uma tendência em criar novas formas de conhecimento que levam a superar os limites corporais do movimento, o homem criou computadores de bordo para os carros, gps, comandos automáticos e ao mesmo tempo se torna cada vez mais dependente do sistema que também falham e que podem apresentar danos irreparáveis ou custosos.

Outro paradigma é que toda a rede de mobilidade é apoiada em uma infraestrutura imóvel e móvel. A primeira é composta por toda malha física que permite que os deslocamentos aconteçam, faz parte dessa estrutura as ruas, os trilhos, os portos, as estações e todo o sistema de energia, iluminação, sinalização e também por redes invisíveis como as redes de fibra ótica . Toda essa composição de elementos permitem que a rede móvel, conformada pelos veículos, possam se movimentar e se complementar.

Se por um lado a mobilidade tem sido considerada um elemento estruturante da gestão pública por outro trouxe questões que provocam reflexões e criam dilemas como o citado por Bertolini (2012) da sua "dependência vs. falta de sustentabilidade". É preciso ampliar a reflexão sobre a transversalidade entre os temas e o sentido da sustentabilidade, sua aplicabilidade e reprodução na esfera urbana. 


\section{CIDADE SUSTENTÁVEL}

O conceito de sustentabilidade urbana vem sendo difundido no mundo desde a metade do século $\mathrm{XX}$, demonstrando uma preocupação por um desenvolvimento equilibrado dentro dos aspectos econômicos, sociais e ambientais. O conceito permite uma combinação de desenvolvimento e uso sustentável dos recursos naturais.

No Brasil, a partir do Estatuto da Cidade, foi ordenado como diretriz da política urbana a garantia do direito a cidades sustentáveis, estabelecendo no art. 2o a mesma como o "direito à terra urbana, moradia, ao saneamento ambiental, à infraestrutura urbana, ao transporte e aos serviços públicos, ao trabalho e lazer, para presentes e futuras gerações." (BRASIL,2001)

A partir dessa diretriz o conceito de sustentabilidade passa a ser relacionado na agenda dos municípios brasileiros, no sentido de planos e projetos, entretanto existe um vazio de propostas para a viabilidade da sua aplicação dentro da realidade das cidades brasileiras, principalmente no que tange a mobilidade urbana.

Como uma das principais caraterísticas do sistema de mobilidade brasileiro está o desrespeito e desprezo pelo transporte coletivo e o estímulo do Estado e da economia pelo uso do transporte motorizado individual, o que torna ainda mais difícil a vida nas metrópoles brasileiras. Como indutor do espraiamento urbano, o automóvel promove a auto segregação social, quando viabiliza a criação de loteamentos distantes do centro e repassa a responsabilidade de promover transporte do Estado para o indivíduo. A aquisição do veículo individual passou a ser muitas vezes, uma condição para acesso a trabalho, lazer e cultura dentro das metrópoles. A noção de favorecer o transporte individual pelo automóvel traz uma ideia emancipação dos deslocamentos. Leva a uma ideia de autonomia do usuário determinados usualmente pela a liberdade do ir e vir contudo essa liberdade do ir e vir sempre esteve condicionada a variáveis econômicas, como o preço de manutenção do automóvel, custo do combustível

Como resposta ao modelo atual de planejamento urbano dos países desenvolvidos, as principais montadoras de automóveis levaram suas indústrias para os países emergentes não só com o objetivo de baratear seu processo de produção industrial, mas com intuito de levar o automóvel para seu principal mercado consumidor, os países em desenvolvimento.

Na contramão da maré internacional de países europeus, onde o automóvel é cada vez mais taxado, o Brasil ainda estimula o uso do veículo individual, tornando o sistema de transporte ainda mais dependente do rodoviarismo, sem deixar espaço para soluções ferroviárias e de veículos não motorizados.

Em 2008, o governo brasileiro reduziu a alíquota do IOF na compra de motocicletas e do IPI da indústria automobilística. Entre 2006 e 2007 houve então um crescimento de 27,8\% e em 
2008 um novo crescimento de 14\% (AFFONSO, 2010) ${ }^{3}$. Os dados são ainda mais alarmantes quando tratamos de subsídios:

"Com relação aos subsídios totais ao transporte urbano nas regiões metropolitanas por modo: autos/motos/táxi recebem de $R \$$ 10,7 bilhões a $R S 24,3$ bilhões/ano ( $86 \%$ dos recursos), enquanto os transportes públicos recebem de $R \$ 2$ bilhões a $R \$ 3,9$ bilhões (14\%), apesar de transportarem $31 \%$ das viagens contra $30 \%$ dos automóveis. Esses subsídios referem-se apenas à compra $e$ licenciamento de veículos, operação direta, estacionamento $e$ externalidades não cobradas (poluição, acidentes, congestionamento)." (AFFONSO,2010)

No Brasil o automóvel ainda é sinônimo de status social, traduzindo o grau de sucesso profissional e financeiro para a aquisição desse tipo de bem e seu uso excessivo em cada deslocamento dentro e fora da cidade. A difusão midiática desse tipo de pensamento atravessa as diferentes classes sociais, mesmo sendo um modelo contraditoriamente inacessível por boa parte da população.

Entretanto não há como demonizar esse tipo de veículo quando tratamos das características das maioria das cidades brasileiras, onde a maioria carece de infraestrutura de transporte e é quase inexistente o planejamento quanto a distribuição de usos e ocupação ao longo da malha urbana. O Estado não possui condições de impossibilitar o uso do transporte automotivo quando encontramos esse tipo de cenário intraurbano. $\mathrm{O}$ caso brasileiro deve ser estudado desde o início do processo implementador do rodoviarismo, buscando-se compreender as possíveis causas e influências desse encadeamento de políticas estimuladoras ao longo do últimos 70 anos.

Para entender melhor o processo basta um olhar para os municípios brasileiros a partir de metade do século XX, quando sofreram um arranque de urbanização com o grande estímulo da economia brasileira ao longo do governo kubitschek. Os "50 anos em $5^{\text {"4 }}$ alavancaram o aparecimento das indústrias e obras públicas, o que traçou o caráter do sistema de transporte brasileiro até os dias de hoje. O rodoviarismo induziu uma série de características territoriais das cidades brasileiras, dentre elas o modelo de cidade espraiada.

O rodoviarismo, segundo Maricato (2011) é responsável pelos principais problemas ambientais das cidades, dos quais é evidente a alta taxa de impermeabilização gerada pelo sistema de transporte que exige asfalto e principal causadora de enchentes. Além de outros impactos

\footnotetext{
${ }^{3}$ AFFONSO, Nazareno . Automóveis e sustentabilidade. 2009. Disponível em: $<$ http://www.ipea.gov.br/desafios/index.php?option=com_content\&view=article\&id=1049:cat id=28\&ltemid=23>. Acesso em: 09 jun. 2018.

${ }^{4}$ O lema do governo do presidente JK, "50 anos em 5", sintetizava seu ideal nacional desenvolvimentista: conduzir o Brasil a um rápido e sólido crescimento econômico, apoiado em três setores essenciais da economia: Indústria, transporte e energia.
} 
negativos que estão se tornando cada vez mais visíveis como o consumo e esgotamento de fontes energéticas, poluição atmosférica e sonora.

Em sua obra Sustentabilidade em urbanizações de pequeno porte (2010), Mascaró retrata a adequação do tipo de pavimentação ao uso do solo em cada situação. Como o autor cita, " $a$ sustentabilidade de um sítio urbano requer um difícil equilíbrio entre o que os humanos precisam de um sítio para morar com conforto e o que a natureza nos permite de alteração. " Assim o mesmo indica a necessidade de impermeabilização apenas em áreas de trânsito intenso.

Em conjunto com a impermeabilização estão outras questões ambientais que envolvem o uso intenso do transporte motorizado individual, como a baixa qualidade do ar, o aquecimento global e o estímulo ao consumo irresponsável de bens duráveis.

Para aprofundamento do tema, podemos classificar o grau de poluição conforme abrangência de cada tipo de poluição gerada. No caso da poluição sonora, por exemplo, seu efeito é perceptível pelos indivíduos inseridos naquele meio de atuação do veículo. Já no caso de poluição com mais abrangência podemos citar a poluição do ar, que se expande com o deslocamento das correntes de ar e pode gerar as chuvas ácidas. Dentre as categorias de poluição produzidas pelo homem a poluição veicular se enquadra como uma das mais recorrentes.

O setor de transporte responde por $20 \%$ das emissões globais de CO2, um dos principais gases do efeito estufa (IPEA, 2011), no Brasil esse número cai para $9 \%$, já que as queimadas chegam a $70 \%$ do total de emissões. Ainda tratando do universo do transporte, o interessante é comparar as diferentes categorias de veículos automotores. Segundo a mesma publicação produzida pelo IPEA, os veículos individuais chegam a produzir $39 \%$ de toda poluição veicular do ar no Brasil, sendo um total de menos de $30 \%$ das viagens realizadas.

\section{Gráfico 1: Emissões de CO2 equivalente no transporte no Brasil em 2006 (em \%)}

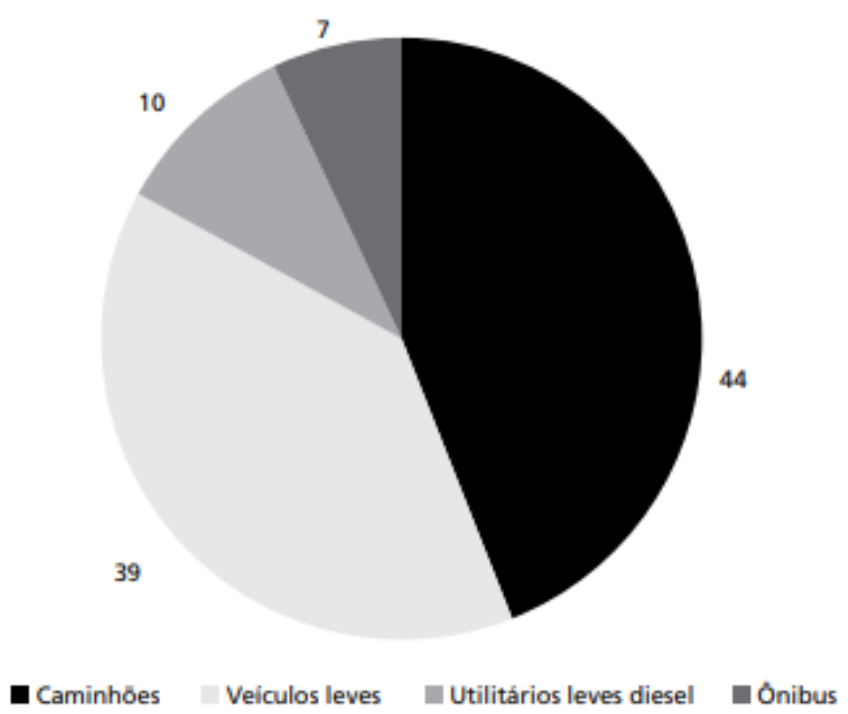


Fonte: IPEA, 2011.

Com base nesses índices é possível perceber o quão o planejamento da mobilidade influi na qualidade ambiental das cidades. A indução do espraiamento urbano pelo uso do automóvel interfere no dia à dia de cada indivíduo, causando a perda de energia, tempo e recursos financeiros. Essas consequências quando refletidas a escala da cidade se apresentam como fator encadeador de perda de recursos públicos direta e indiretamente. Direto quando se observa os gastos em transporte, e indiretamente ao encarar a realidade dos hospitais com vítimas de acidentes de trânsito e a necessidade de readequação de recursos para infra estrutura urbana, por exemplo.

Segundo Banister (2007), as medidas necessárias para alcançar a mobilidade sustentável das cidades já são conhecidas, contudo o paradigma mais difíceis de se enfrentar vão além das medidas reais e buscam entender como mudar uma mentalidade de responsabilidade coletiva.

\section{CONCLUSÃO}

Como reflexo desse artigo, buscou-se a análise do cenário das cidades brasileiras para compor a priori, um diagnóstico para que seja possível corroborar futuramente para a elaboração de um modelo de cidade sustentável, onde seja possível prover qualidade do meio urbano e inclusão social de todos os recurso disponíveis na cidade.

O tema possui uma complexidade que necessita de um maior aprofundamento em cada uma das categorias que compreendem a cidade sustentável (econômico, social e ambiental), onde se estabelece a próxima etapa do processo da pesquisa.

Como tema central abordado, a mobilidade urbana retrata o princípio do planejamento urbano, orientando o arranjo espacial das cidades. Segundo o Planmob: Caderno de Referência para o Plano de Mobilidade Urbana, organizado pela Secretaria Nacional de Transporte e da Mobilidade Urbana de 2015, a $\mathrm{PNMU}^{5}$ pretendia a inter-relação entre o uso do solo e a mobilidade urbana, disseminando o conceito de mobilidade como fator inerente ao planejamento urbano:

É marcante na PNMU o resgate do uso do solo urbano por meio da mobilidade urbana sustentável, ou seja, ambiental, econômica e socialmente sustentável. Assim, a Lei da Mobilidade Urbana privilegia o transporte não motorizado em detrimento do motorizado e o público coletivo em detrimento do individual motorizado(art. 6, II) (2015, pág. 29)

Um sistema de mobilidade urbana sustentável já deveria existir na pauta do governos seja na escala municipal, estadual ou federal, como medida estruturadora do processo de planejamento urbano. A lacuna entre Estatuto da Cidade (2001) e a PNMU (2012) no tema de mobilidade sustentável reverbera a lacuna ainda maior entre os mesmo e a Constituição de

\footnotetext{
${ }^{5}$ Política Nacional de Mobilidade Urbana, estabelecida através da Lei 12.587/12.
} 
1988, dificultando a transmissão de um conceito de planejamento atrelado a mobilidade urbana, contribuindo para a ausência de medidas de cunho municipal para o setor.

As políticas públicas que visam controlar a poluição veicular tem atuação apenas no controle de emissão de gases poluentes dos veículos, falhando no sentido primordial da proposta, onde deveriam ser aplicadas medidas que restrinjam o uso dos automóveis, por meio de pedágios, proibição de estacionamentos e circulação em determinadas áreas. Entretanto, como maior desestimulador do uso dos veículos individuais está o estímulo ao uso dos coletivos, por meio de subsídios para baratear o valor das passagens e melhoria da qualidade das frotas. Somente assim será possível promover sustentabilidade urbana dentro das cidades brasileiras.

\section{AGRADECIMENTO}

Agradecemos a CAPES por possibilitar os recursos fundamentais a pesquisa e a Escola de Arquitetura e Urbanismo da Universidade Federal Fluminense.

\section{REFERÊNCIAS BIBLIOGRÁFICAS}

AFFONSO, Nazareno . Automóveis e sustentabilidade. 2009. Disponível em: <http://www.ipea.gov.br/desafios/index.php?option=com_content\&view=article\&id=1049:catid=28\&/temid=23> Acesso em: 09 jun. 2018.

BANISTER, David. The Sustainable Mobility Paradigm. Volume 15, Issue 2. Oxford: Revista Transport Policy, 2007. 73-8p.

BERTOLINI, Luca. Integrating mobility and urban development agendas: a manifesto. Volume 48, 2012 - Issue 1. Amsterdam: Journal disP - The Planning Review, 2012. 15-26p.

BRASIL. Lei 10.257 de 10 de julho de 2001: Regulamenta os artigos 182 e 183 da Constituição Federal, estabelece diretrizes gerais da política urbana e dá outras providências. Brasília: Congresso Nacional, 2001.

BRASIL. Lei 12.587, de 3 de Janeiro de 2012: diretrizes da Política Nacional de Mobilidade Urbana. Brasília; Congresso Nacional , 2012.

FRANÇA, Júnia Lessa et al. Manual para normalização de publicações técnico-científicas. 6. ed. rev. e ampl. Belo Horizonte: UFMG, 2003. 230 p.

IBGE. Normas de apresentação tabular. 3. ed. 1993.

ITDP. Caderno de Referência para Elaboração de Plano de Mobilidade Urbana (PlanMob). Brasil: Ministério das Cidades, 2015. Disponível em: http://itdpbrasil.org.br/planmob/ . Acesso em: 01 de Jun., 2018.

LAKATOS, Eva Maria; MARCONI, Marina de Andrade. Fundamentos de metodologia científica. 3. ed. rev. e ampl. São Paulo: Atlas, 1991. 270 p.

MARICATO, Ermínia. Diálogos: Ermínia Maricato. 1. 2018. Disponível em: <https://www.youtube.com/watch?v=9MvqeZi1Qko\&feature=youtu.be>. Acesso em: 01 jun. 2018.

MARICATO, E. (2011). A cidade sustentável. 9o Congresso Nacional DE Sindicatos de Engenheiros - CONSENGE Porto Velho, 2011. 7-32p. Disponível em::http//www.sengemg.com.br/downloads/eventos/9_consenge/cadernoteses-2- Consenge.pdf. Acesso em: 9 de jun., 2018.

MASCARÓ, Juan Luis. (Org.) Sustentabilidade em Urbanizações de Pequeno Porte. Porto Alegre: Masquatro, 2010. 


\section{Periódica Eletrânica

SHELLER, Mimi; URRY, John. New mobilities paradigm. Lancaster: Environment and Planning A, 2006. volume 38, $207-226 p$

RIBEIRO DE CARVALHO, Carlos Henrique . EMISSÕES RELATIVAS DE POLUENTES DO TRANSPORTE MOTORIZADO DE PASSAGEIROS NOS GRANDES CENTROS URBANOS BRASILEIROS. 1. ed. Brasília: IPEA, 2011. 42 p. v. 1. Disponível em: <http://www.en.ipea.gov.br/agencia/images/stories/PDFs/TDs/td_1606.pdf>. Acesso em: 10 jun., 2018.

VASCONCELLOS, Eduardo. Transporte urbano, espaço e equidade: análise das políticas públicas. 1. ed. São Paulo: Annablume, 2001. 218 p. v. 1.

Mobilidade Urbana e Cidadania. São Paulo: Editora SENAC, 2012.

Políticas de Transporte no Brasil: a construção da mobilidade excludente. São Paulo: Manole, 2013. 